\title{
Article \\ Harmonic and Vibration Analysis of Dual Three-Phase PMSM with One-Phase Open Circuit Fault
}

\author{
Shihao Zhao ${ }^{1,2}$, Jinhua Chen ${ }^{1, *}$, Yunpeng Gao ${ }^{1}$ and Chi Zhang ${ }^{1}$ \\ 1 Labortory of Robotics and Intelligent Manufacturing Equipment Technology of Zhejiang Province, \\ Ningbo Institute of Materials Technology and Engineering, Chinese Academy of Sciences, \\ Ningbo 315201, China; zhaoshihao@nimte.ac.cn (S.Z.); gaoyunpeng@nimte.ac.cn (Y.G.); \\ zhangchi@nimte.ac.cn (C.Z.) \\ 2 School of Electrical Engineering, Hebei University of Science and Technique, Shijiazhuang 050018, China \\ * Correspondence: chenjinhua@nimte.ac.cn
}

Citation: Zhao, S.; Chen, J.; Gao, Y.; Zhang, C. Harmonic and Vibration Analysis of Dual Three-Phase PMSM with One-Phase Open Circuit Fault. Symmetry 2022, 14, 290. https:// doi.org/10.3390/sym14020290

Academic Editor: Jan Awrejcewicz

Received: 7 January 2022

Accepted: 26 January 2022

Published: 31 January 2022

Publisher's Note: MDPI stays neutral with regard to jurisdictional claims in published maps and institutional affiliations.

Copyright: (c) 2022 by the authors. Licensee MDPI, Basel, Switzerland. This article is an open access article distributed under the terms and conditions of the Creative Commons Attribution (CC BY) license (https:/ / creativecommons.org/licenses/by/ $4.0 /)$.

\begin{abstract}
This paper analyzes the harmonics and vibration under different fault-tolerant current control when one-phase winding of dual three-phase permanent magnet synchronous motor (PMSM) is an open circuit fault. Firstly, the dual three-phase load condition subdomain model of breadloaf surface-mounted permanent magnet (PM) PMSM is established. Secondly, the working conditions of an open circuit fault of one-phase winding are set from the perspectives of no fault-tolerant (NFT) control, maximum torque (MT) control, minimum copper loss (MCL) control and single three-phase mode (STPM) control. The torque harmonics and electromagnetic force harmonics of the four working conditions are analyzed. Then, considering the multi-physical field of electromagnetic and structural coupling, the electromagnetic force in the motor air gap acts on the stator core, and the vibration under four different working conditions is calculated and analyzed. Through the comparison between the analytical method and finite element method, the accuracy of the established model is verified. The calculation method is effective and accurate, it can quickly predict the motor performance in case of one-phase open circuit fault of dual three-phase PMSM.
\end{abstract}

Keywords: subdomain method; open circuit fault; harmonic analysis; electromagnetic vibration; dual three-phase motor

\section{Introduction}

Polyphase permanent magnet synchronous motors (PPMSMs) have attracted more and more attention in ship propulsion, electric vehicles, wind power generation and other applications. Compared with three-phase motors, PPMSMs have the advantages of low voltage, high power, low vibration noise and multi degree of freedom control [1,2], the most prominent is that with the increase of phase numbers, its control degree of freedom increases. Therefore, more fault-tolerant control methods can be realized in case of motor winding fault [3].

The prediction method of motor vibration has always been the focus of many researchers. The finite element(FE) method can accurately simulate and analyze the vibration results of the motor, but the calculation of multi-physical field coupling is very timeconsuming. The sub domain method (SM) divides the motor into multiple structural domains and quickly calculates the air gap magnetic field results of the motor in combination with the boundary conditions. It can achieve the same calculation accuracy as the finite element method [4-7]. Based on the electromagnetic force calculated by analytical method and the modal calculation results, the vibration of the motor can be calculated quickly.

Open circuit fault of winding is very common in AC motors. Solder melting caused by long-term high-temperature operation, action of mechanical force and electromagnetic force, switching fault of inverter and other reasons may lead to open circuit of motor winding [8]. Considering the steady-state operation of the motor, there are many solutions 
to the amplitude and phase of each phase current under this assumption as long as the total magnetomotive force (MMF) before and after the fault is kept unchanged. Reference [9] proposed a fault-tolerant control scheme to minimize copper loss and maximize torque with MT per ampere. In reference [10], in order to obtain the MT of the given maximum peak current, a remedial method for the current amplitude and phase of the remaining phase windings is proposed. In reference [11], a fault-tolerant hybrid current control method is proposed by combining single-phase three-phase mode control with maximum torque control. Reference [12] established the mathematical model of one-phase open circuit dual three-phase PMSM according to four different neutral connection modes under fault state, and derived the MCL vector control strategy under four conditions. Finally, different models were compared. Reference [13] proposed a single index fault detection method, which, together with natural fault-tolerant control, enhances the robustness with minimum complexity. In reference [14], a method based on variable ratio after vector space decomposition is used to study the diagnosis of incomplete phase fault, which can quickly detect and locate the fault phase. According to the principle of constant stator magnetic potential and aiming at the MCL, reference [15] optimized the current of dual three-phase PMSM without one-phase winding.

Although the PPMSMs have high fault-tolerance and many degrees of freedom of fault-tolerant control in case of winding open circuit fault, the motor will inevitably produce torque ripple and more electromagnetic harmonics after a winding fault. Even if the corresponding fault-tolerant control is adopted, the harmonic component will still be increased and electromagnetic vibration will be generated due to the operation of asymmetric phase. Therefore, the prediction and analysis of harmonics and vibration after a polyphase winding fault can better evaluate the operation state and performance after an open circuit fault of motor winding.

In this paper, the magnetic field calculation model of breadloaf PM dual three-phase PMSM under load conditions is established, based on the SM. It is assumed that the open circuit fault of one-phase winding is the unbalanced operation condition of motor fault. Firstly, a variety of fault-tolerant strategy models are established, that is, NFT control, MT control, MCL control and STPM control. Then, under different fault-tolerant conditions, the torque harmonics, electromagnetic force harmonics and vibration of the motor are analyzed by using the FE method and analytical model. The results show the effectiveness and accuracy of the analytical method. It provides a basis for studying the winding open circuit fault of dual three-phase PMSM.

\section{Magnetic Field Modeling and Winding Open Circuit Fault Setting}

\subsection{Subdomain Model of Dual Three-Phase Motor}

In this paper, a dual three-phase PMSM with 96 slots and 16 poles is studied, the structural parameters of the motor are shown in Table 1. In order to reduce the vibration of the motor, the motor structure is designed with integer slots and double-stacked windings in the form of spatial arrangement. The PMs are of breadloaf structure and the air gap length is increased to $5 \mathrm{~mm}$. The reason for the long air gap length is that this motor is used in underwater propulsion, therefore, compared with the industrial motor, the designed motor harmonic is lower. If the FE method is used to calculate and analyze the motor, whether it is a single electromagnetic field calculation or multi physical field coupling calculation, the consideration of harmonics and vibration has high requirements for the grid quality in the process of quantitative analysis. This paper uses the mutual verification of analytical method and finite element method to consider the open circuit of one phase of winding. 
Table 1. Parameters of the simulated motor.

\begin{tabular}{ccc}
\hline Symbol & Quantity & Value (Units) \\
\hline$Q_{s} / p / m$ & Slots/Pole pair/Phase & $96 / 8 / 6$ \\
$R_{o}$ & Stator outer radials & $182.5(\mathrm{~mm})$ \\
$R_{i}$ & Stator inner radials & $150(\mathrm{~mm})$ \\
$L_{s t}$ & Stator core length & $20(\mathrm{~mm})$ \\
$\delta$ & Air gap length & $5(\mathrm{~mm})$ \\
$h_{m}$ & Magnet maximum thickness & $6(\mathrm{~mm})$ \\
$B_{r}$ & Magnet remanence & $1.38(\mathrm{~T})$ \\
$\alpha_{p}$ & Pole-arc coefficient & 0.89 \\
$n_{r}$ & Speed mech & $600(\mathrm{rpm})$ \\
\hline
\end{tabular}

The structural view of the motor is shown in Figure 1a, and the precise SM of surfacemounted PMSM studied in this paper is established, as shown in Figure $1 \mathrm{~b}$ and Equation (1), including breadloaf PM sub domain, air gap sub domain, stator slot sub domain and stator slot sub domain [6]. In Equation (1), $A_{r j}, A_{a i r}, A_{s o i}$ and $A_{s l i}$ represent the vector magnetic potential in each subdomain, $\mu_{0}$ is the vacuum permeability, and its value is $4 \pi \times 10^{-7} \mathrm{~T} \cdot \mathrm{m} / \mathrm{A}, M_{r j}$ and $M_{\theta j}$ represent the magnetization of the permanent magnet, $J$ is a matrix, which represents the current density and winding distribution.

$$
\begin{cases}\frac{\partial^{2} A_{r j}}{\partial r^{2}}+\frac{1}{r} \frac{\partial A_{r j}}{\partial r}+\frac{1}{r^{2}} \frac{\partial^{2} A_{r j}}{\partial \theta^{2}}=-\frac{\mu_{0}}{r}\left(M_{\theta j}-\frac{\partial M_{r j}}{\partial \theta}\right) \text { Magnet } \\ \frac{\partial^{2} A_{a i r}}{\partial r^{2}}+\frac{1}{r} \frac{\partial A_{a i r}}{\partial r}+\frac{1}{r^{2}} \partial^{2} A_{a i r} & =0 \quad \text { Air-gap } \\ \frac{\partial^{2} A_{s o i}}{\partial r^{2}}+\frac{1}{r} \frac{\partial A_{s o i}}{\partial r}+\frac{1}{r^{2}} & \frac{\partial^{2} A_{s o i}}{\partial \partial^{2}}=0 \quad \text { Slot-opening } \\ \frac{\partial^{2} A_{s l i}}{\partial r^{2}}+\frac{1}{r} \frac{\partial A_{s l i}}{\partial r}+\frac{1}{r^{2}} \frac{\partial^{2} A_{s l i}}{\partial \theta^{2}}=-\mu_{0} J & \text { Stator-slot }\end{cases}
$$

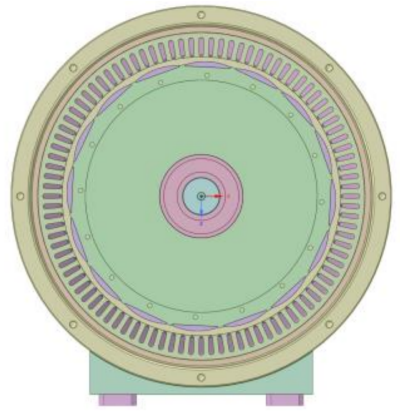

(a)

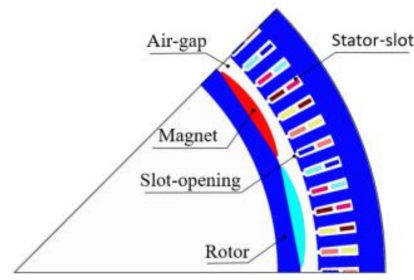

(b)

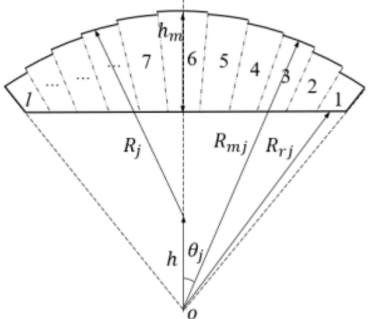

(c)

Figure 1. Dual three-phase motor model: (a) Motor structure model; (b) SM model; (c) Permanent magnet model.

As shown in Figure 1c, for breadloaf PM, the equivalent modeling of multi-section PM is divided by the equal pole arc coefficient method, and the included angle between the magnetic pole of section $j$ and the center line of $\mathrm{PM} \theta_{j}$ can be expressed as:

$$
\theta_{j}=\frac{\alpha_{p} \pi}{p}\left(\frac{l-2 j+1}{2 l}\right)
$$

where $l$ is the number of segments of PM, $\alpha_{p}$ is the pole arc coefficient of the PM, $p$ is the pole-pair number of the motor, the outer radius $R_{m j}$ and inner radius $R_{j}$ of the $j$-segment PM can be expressed as:

$$
R_{m j}=h \cos \theta_{j}+\sqrt{\left(h \cos \theta_{j}\right)^{2}-\left(h^{2}-R_{j}^{2}\right)}
$$




$$
R_{r j}=R_{r} \cos \left[\alpha_{p} \pi /(2 p)\right] / \cos \theta_{j}
$$

where $R_{r}$ is the maximum outer diameter of rotor core, $R_{m}$ is the maximum outer diameter of PM, the center position angle of section $j$ PM $\alpha_{j}$ and polar arc coefficient $\alpha_{p j}$ can be expressed as:

$$
\left\{\begin{array}{l}
\alpha_{j}=\frac{\pi}{2 p}-\theta_{j} \\
\alpha_{p j}=\frac{\alpha_{p}}{l}
\end{array}\right.
$$

Through the variable separation method, the general solution of the equation established in each sub domain is solved. Equation (1) is used to solve the results of each magnetic pole magnetic field. The synthetic magnetic field is equivalent to the superposition of the magnetic field contributions of each segment of PM

$$
\left\{\begin{array}{l}
B_{a i r, r}=\sum_{j=1}^{l} B_{a i r, r j}=\sum_{j=1}^{l} \frac{1}{r} \frac{\partial A_{a i r}(r, \theta)}{\partial \theta} \\
B_{a i r, \theta}=\sum_{j=1}^{l} B_{a i r, \theta j}=\sum_{j=1}^{l}-\frac{\partial A_{a i r}(r, \theta)}{\partial r}
\end{array}\right.
$$

For the motor analyzed in this paper, the radial component and tangential component of air gap magnetic flux density calculated by SM method and FE method under load current is shown in Figure 2, it can be seen that the SM result has high calculation accuracy.

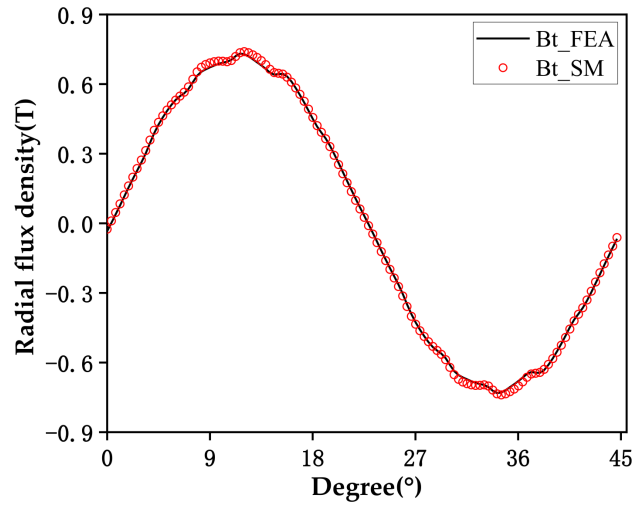

(a)

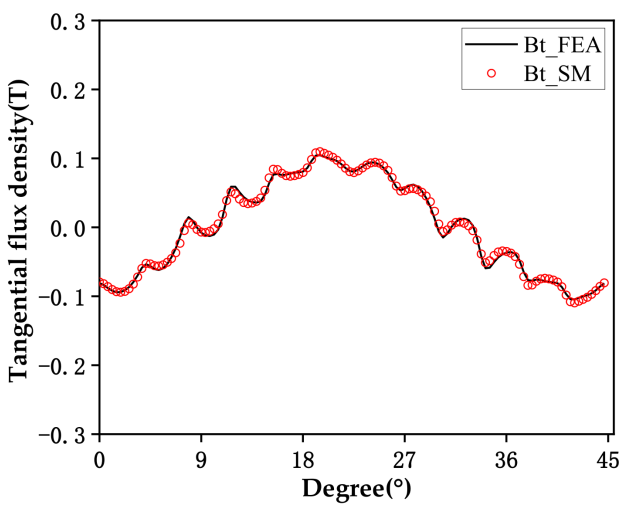

(b)

Figure 2. Air gap magnetic flux density under load condition: (a) Radial component; (b) Tangential component.

\subsection{Open Circuit Fault Condition Setting}

When the motor winding works normally in dual three-phase mode (DTPM), the current of each phase is shown in Figure 3a, the current phase difference between the two sets of windings is $30^{\circ}$. The armature magnetic field distribution conforms to the topology principle of dual three-phase motor in Figure $3 \mathrm{~b}$.

The motor with two neutral points analyzed is an integer slot multi-phase winding structure with double-layer short distance distribution. It is assumed that the winding is sinusoidal distribution without considering the spatial harmonics of the winding distribution coefficient. As shown in Figure 4, if the F-phase winding suddenly has an open circuit fault, after a short transient process, the current of the F-phase winding immediately becomes $0 \mathrm{~A}$. 


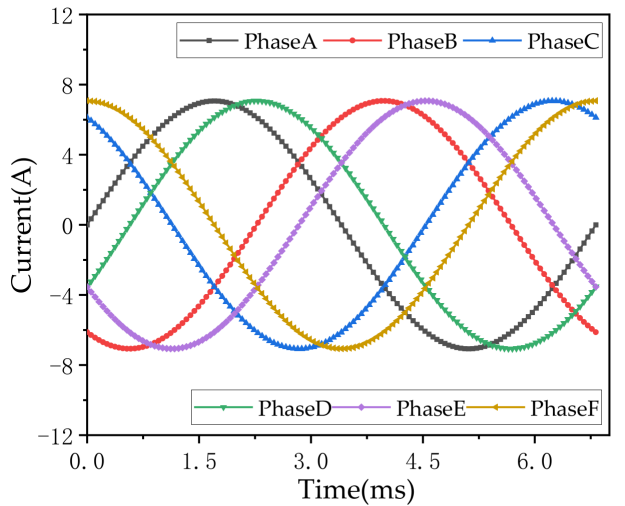

(a)

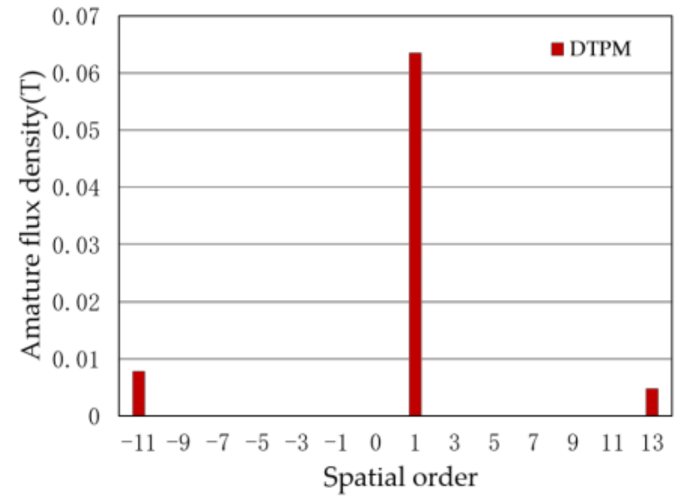

(b)

Figure 3. Armature characteristics before the fault: (a) Phase current waveform; (b) FFT2 results of radial component of armature flux density.

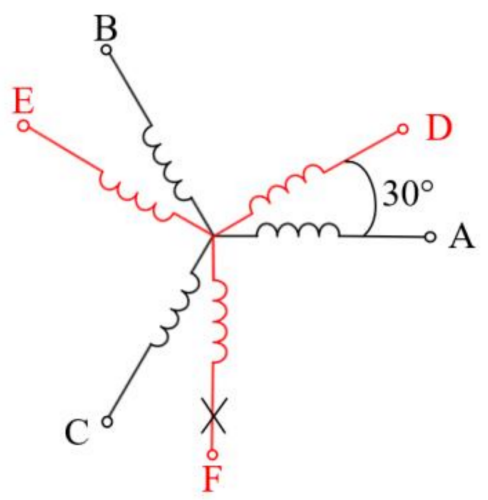

Figure 4. Star diagram of winding open circuit fault.

The $M M F$ of the winding before the fault can be expressed as

$$
\begin{aligned}
M M F & =N_{A} i_{A}+N_{B} i_{B}+N_{C} i_{C}+N_{D} i_{D}+N_{E} i_{E}+N_{F} i_{F} \\
& =\frac{N_{t}}{2}\left[i_{A} \cos (\varphi)+i_{B} \cos \left(\varphi-\frac{2 \pi}{3}\right)+i_{C} \cos \left(\varphi-\frac{4 \pi}{3}\right)\right]+ \\
& \frac{N_{t}}{2}\left[i_{D} \cos \left(\varphi-\frac{\pi}{6}\right)+i_{E} \cos \left(\varphi-\frac{5 \pi}{6}\right)+i_{F} \cos \left(\varphi-\frac{9 \pi}{6}\right)\right] \\
& =\frac{3}{2} N_{t} I_{m} \cos (\omega t-\varphi)
\end{aligned}
$$

Winding MMF of phase F open circuit will be the sum of the remaining five phases:

$$
\begin{aligned}
M M F^{\prime} & =N_{A} i_{A}+N_{B} i_{B}+N_{C} i_{C}+N_{D} i_{D}+N_{E} i_{E} \\
& =\frac{N_{t}}{2}\left[i_{A} \cos (\varphi)+i_{B} \cos \left(\varphi-\frac{2 \pi}{3}\right)+i_{C} \cos \left(\varphi-\frac{4 \pi}{3}\right)+i_{D} \cos \left(\varphi-\frac{\pi}{6}\right)+i_{E} \cos \left(\varphi-\frac{5 \pi}{6}\right)\right]
\end{aligned}
$$

where $N_{t}$ is the number of winding turns, $I_{m}$ is the current amplitude and $\omega$ is the electrical angular frequency, $\varphi$ is the winding space angle.

According to Kirchhoff's law, the remaining healthy phase winding current can be expressed as:

$$
\begin{aligned}
& i_{A}+i_{B}+i_{C}=0 \\
& i_{D}+i_{E}=0
\end{aligned}
$$

In case of open circuit fault of one-phase winding, the motor will produce a large torque ripple. In order to pursue a stable output torque, the remaining synthetic magnetomotive force should remain the same as before the failure, that is, $M M F=M M F^{\prime}$, the solution of the reconstructed linear equations is not unique, so it can be used for motor optimization after phase loss $[10,11]$. 
Based on the SM, current excitation is applied to the stator slot winding. For the spatial arrangement of double three-phase windings of the unit motor (12 slots 2 poles), as shown in Equation (12), the row vector of the winding matrix $M_{c}$ represents the slot position, the column vector represents the phase position of the winding, 1 and -1 represent the inflow and outflow of current, and $k_{f}$ and $S_{c}$ represent the filling range and area of the winding in the slot

$$
\begin{aligned}
& J(t)=\frac{k_{f}}{S_{c}} i(t) M_{c} \\
& i(t)=\left[\begin{array}{llllll}
i_{A} & i_{B} & i_{C} & i_{D} & i_{E} & i_{F}
\end{array}\right] \\
& M_{\mathcal{C}}=\left[\begin{array}{rrrrrrrrrrrr}
1 & 0 & 0 & 0 & 0 & -1 & -1 & 0 & 0 & 0 & 0 & 1 \\
0 & 0 & 0 & 1 & 1 & 0 & 0 & 0 & 0 & -1 & -1 & 0 \\
0 & -1 & -1 & 0 & 0 & 0 & 0 & 1 & 1 & 0 & 0 & 0 \\
1 & 1 & 0 & 0 & 0 & 0 & -1 & -1 & 0 & 0 & 0 & 0 \\
0 & 0 & 0 & 0 & 1 & 1 & 0 & 0 & 0 & 0 & -1 & -1 \\
0 & 0 & -1 & -1 & 0 & 0 & 0 & 0 & 1 & 1 & 0 & 0
\end{array}\right] \begin{array}{c}
\text { windingA } \\
\text { windingB } \\
\text { windingC } \\
\text { windingD } \\
\text { windingE }
\end{array}
\end{aligned}
$$

In this paper, the changes of current amplitude and phase of other healthy phases after missing one phase fault are considered from the perspectives of NFT control, MT control, MCL control and STPM control.

\subsubsection{No Fault Tolerant Control}

When the F-phase winding has an open-circuit fault, no fault-tolerant strategy is adopted. The motor armature winding can be equivalent to a combination of three-phase motor winding and single-phase motor winding, and the current amplitude of D-phase and E-phase becomes $\sqrt{3} / 2$ the original, the phase leads and lags the original $30^{\circ}$, respectively, at this time the phase difference is $180^{\circ}$, the fault tolerant current can be expressed as Equation (13) and Figure 5a.

$$
\left\{\begin{array}{l}
i_{A}=I_{m} \sin (\omega t) \\
i_{B}=I_{m} \sin (\omega t-2 \pi / 3) \\
i_{C}=I_{m} \sin (\omega t-4 \pi / 3) \\
i_{D}=\sqrt{3} / 2 \cdot I_{m} \sin (\omega t) \\
i_{E}=\sqrt{3} / 2 \cdot I_{m} \sin (\omega t-\pi)
\end{array}\right.
$$

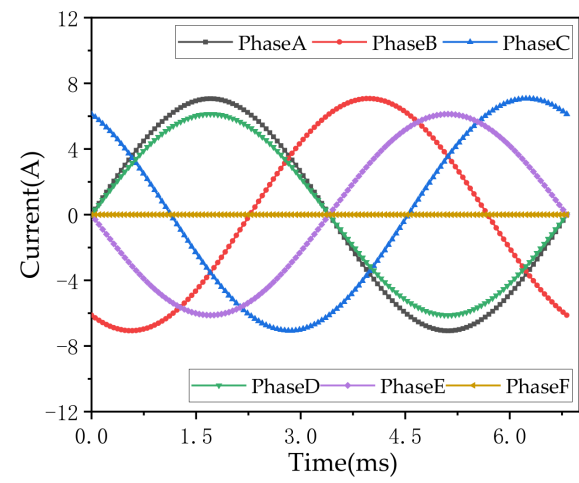

(a)

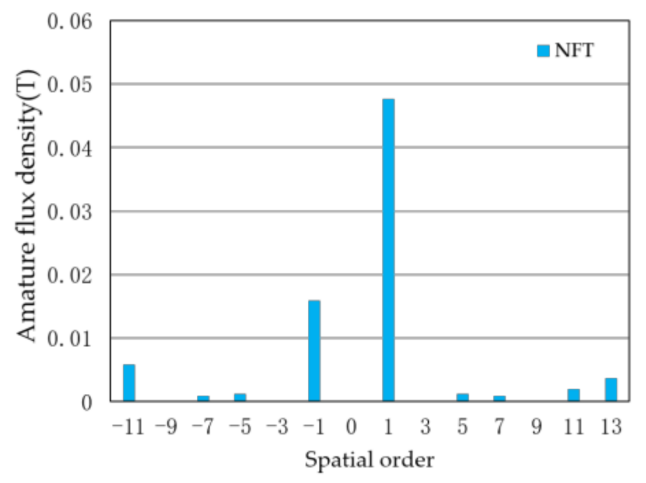

(b)

Figure 5. Armature characteristics of NFT control: (a) Phase current waveform; (b) FFT2 results of radial component of armature flux density.

\subsubsection{Maximum Torque Control}

According to references $[10,11]$, one-phase winding of a dual three-phase PMSM is open circuit, and the remedial measures for the current amplitude and phase of the remaining phases, if the pursuit of MT is the goal, according to Lagrange, the daily multi- 
plier method solves Equations (7)-(9) as a condition, and its fault-tolerant current can be expressed as Equation (15) and Figure 6a.

$$
\begin{aligned}
& T_{\max }=\max \left(i_{A}^{2}, i_{B}^{2}, i_{C}^{2}, i_{D}^{2}, i_{E}^{2}\right) \\
& \left\{\begin{array}{l}
i_{A}=0 \\
i_{B}=\sqrt{3} I_{m} \sin (\omega t) \\
i_{C}=\sqrt{3} I_{m} \sin (\omega t-\pi) \\
i_{D}=\sqrt{3} I_{m} \sin (\omega t-3 \pi / 2) \\
i_{E}=\sqrt{3} I_{m} \sin (\omega t-\pi / 2)
\end{array}\right.
\end{aligned}
$$

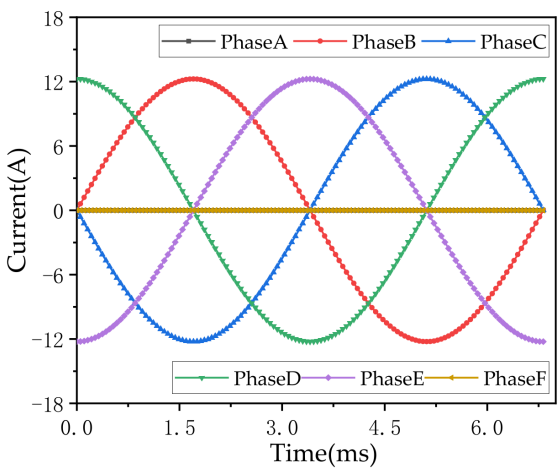

(a)

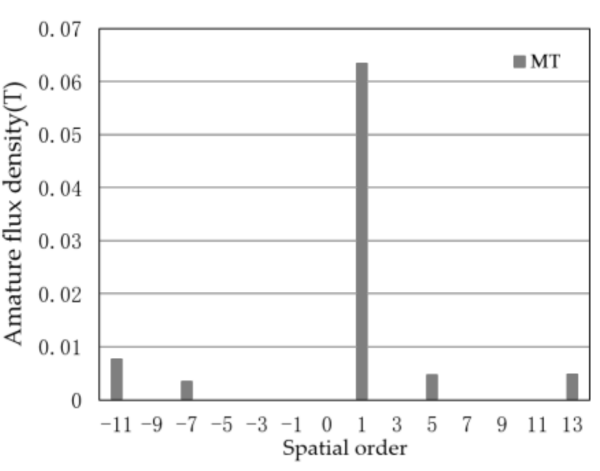

(b)

Figure 6. Armature characteristics of MT control: (a) Phase current waveform; (b) FFT2 results of radial component of armature flux density.

\subsubsection{Minimum Copper Loss Control}

According to references [11,14], if the goal is to obtain the MCL, use Equations (7)-(9) to solve Equation (16) by the Lagrangian multiplier method, and amplitude and phase of the fault-tolerant current can be expressed as Equation (17) and Figure 7a.

$$
\begin{gathered}
\operatorname{Loss}_{C u}=R_{S}\left(i_{A}^{2}+i_{B}^{2}+i_{C}^{2}+i_{D}^{2}+i_{E}^{2}\right) \\
\left\{\begin{array}{l}
i_{A}=I_{m} \sin (\omega t-\pi / 2) \\
i_{B}=-0.5 I_{m} \sin (\omega t-\pi / 2)+\sqrt{3} I_{m} \sin (\omega t) \\
i_{C}=-0.5 I_{m} \sin (\omega t-\pi / 2)-\sqrt{3} I_{m} \sin (\omega t) \\
i_{D}=\sqrt{3} / 2 \cdot I_{m} \sin (\omega t-\pi / 2) \\
i_{E}=-\sqrt{3} / 2 \cdot I_{m} \sin (\omega t-\pi / 2)
\end{array}\right.
\end{gathered}
$$

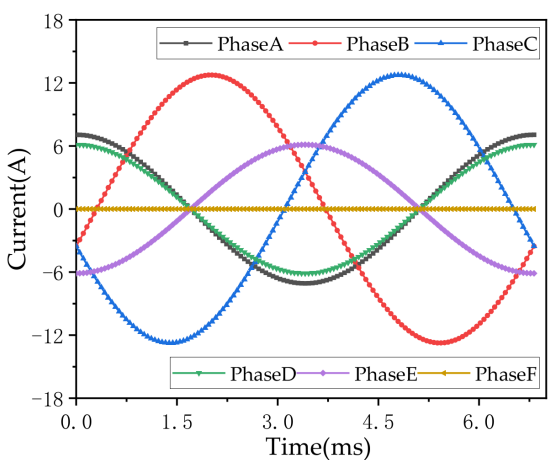

(a)

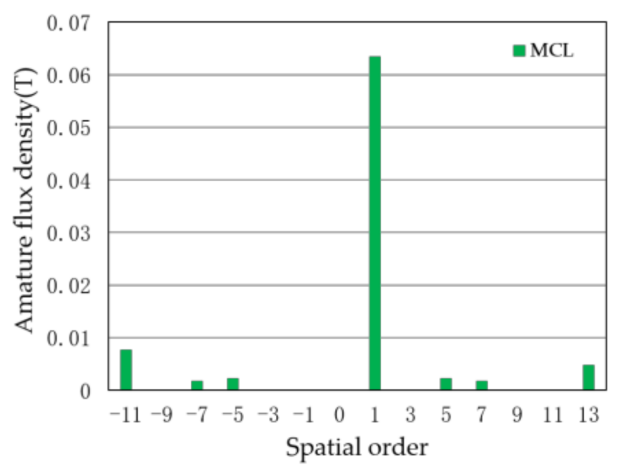

(b)

Figure 7. Armature characteristics of MCL control: (a) Phase current waveform; (b) FFT2 results of radial component of armature flux density. 


\subsubsection{Single Three-Phase Mode Control}

For the dual three-phase PMSM with neutral isolation, whether one or more phases of a set of windings fail, the whole set of windings can be cut off, and the motor is controlled by a single three-phase. At this time, the winding armature current is shown in Figure 8a.

$$
\left\{\begin{array}{l}
i_{A}=I_{m} \sin (\omega t) \\
i_{B}=I_{m} \sin (\omega t-2 \pi / 3) \\
i_{C}=I_{m} \sin (\omega t-4 \pi / 3) \\
i_{D}=i_{E}=i_{F}=0
\end{array}\right.
$$

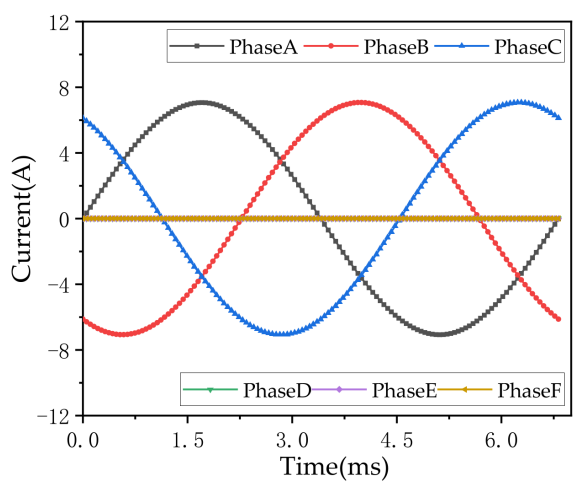

(a)

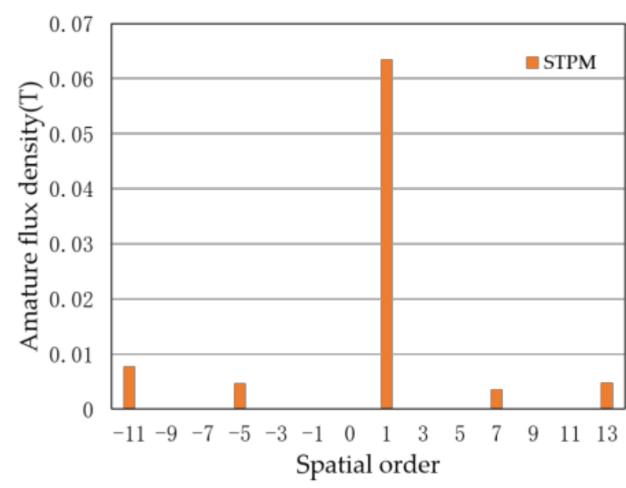

(b)

Figure 8. Armature characteristics of STPM control: (a) Phase current waveform; (b) FFT2 results of radial component of armature flux density.

As shown in Figure 9, the armature flux density under various working conditions is decomposed by a two-dimensional Fourier transform. This paper is based on the study of sinusoidal current, and the spatial harmonic distribution is shown in Table 2. The harmonic distribution of the armature flux density before winding fault is $12 v+1$. The direction of component -1 which is opposite to the fundamental component if motor adopts NFT control, so the rotating magnetic field will produce large harmonic components twice the electrical frequency, the armature magnetic field harmonic with order of $6 v \pm 1$ will produce load torque fluctuation with frequency of $|6 v \pm 1-1| f$, MCL control is the same. If the motor adopts MT control, when $v$ is odd, the motor generates $|6 v-2| f$ torque harmonics, and when $v$ is even, the motor generates $|6 v| f$ torque harmonics, STPM control contains only $|6 v| f$ torque harmonics. It can be seen that the descending order of the harmonic content of the motor under the four control modes is STPM, MT, MCL, NFT. In the above analysis, $v$ is integral number, $f$ is the electrical frequency of motor operation that it can be calculated by $n_{r} p / 60$.

Table 2. Harmonic distribution of armature magnetic field under different working conditions.

\begin{tabular}{cccccc}
\hline & DTPM & NFT & MT & MCL & STPM \\
\hline Fundamental component & 1 & -1 and 1 & 1 & 1 & 1 \\
Harmonic component & $12 v+1$ & $6 v \pm 1$ & $6 v-1, v$ is odd & $6 v \pm 1$ & $6 v+1$ \\
\hline
\end{tabular}




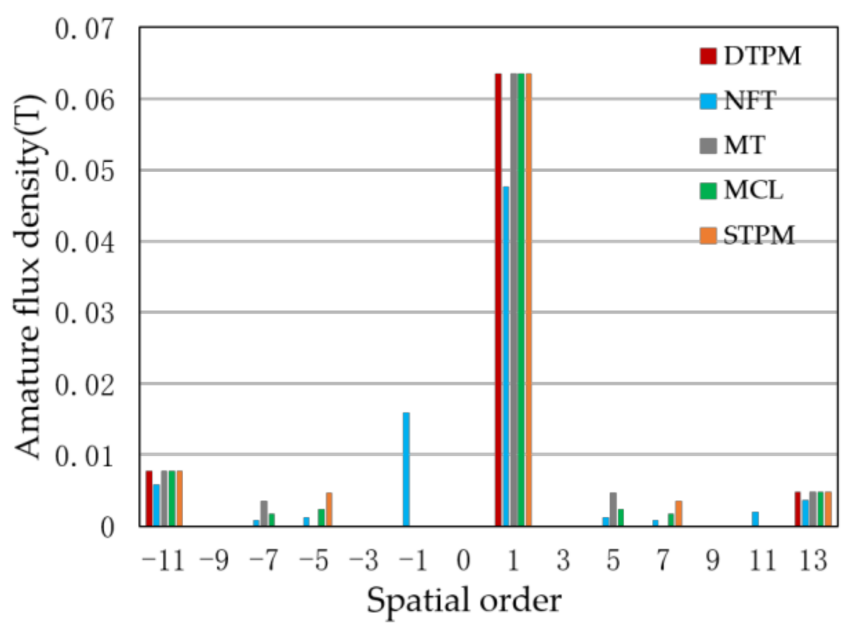

Figure 9. All the FFTs of the armature flux density.

\section{Harmonic Analysis}

\subsection{Torque Harmonic Analysis}

The motor torque result is calculated by integrating the product of the radial component and tangential component of magnetic density on rail in the middle of air gap [6], where $R_{a i r}$ is the radius in the middle of the air gap, $L_{s t}$ is the axial length of motor.

$$
T_{e}=\frac{L_{s t} R_{\text {air }}^{2}}{\mu_{0}} \int_{0}^{2 \pi} B_{r}\left(R_{\text {air }}, \theta\right) B_{t}\left(R_{\text {air }}, \theta\right) d \theta
$$

According to the analysis in Section 2, the stable output torque is obtained based on the principle of constant MMF. If the motor can still output the rated torque, the current amplitude under STPM control should be twice the original. After setting the appropriate initial position of the rotor, ensure that the motor output torque under the three faulttolerant controls is close to the rated torque. As shown in Figure 10b, the average torque of MT control and MCL control is $26.95 \mathrm{~N} \cdot \mathrm{m}$, and the average value of STPM control is $27.08 \mathrm{~N} \cdot \mathrm{m}$. In one electric cycle, the period of output-torque waveform calculated under the four control modes is two, four, two and six. In addition, if the motor adopts NFT control method, although the current amplitude and phase of winding D and winding $\mathrm{E}$ will change, as shown in Figure 10a, the imbalance of the motor magnetic field will lead to large torque ripple.

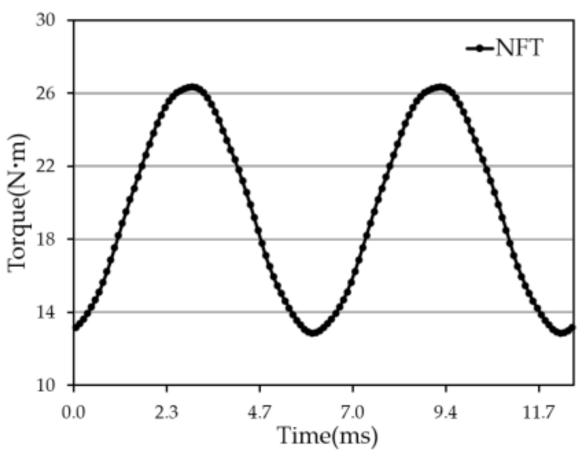

(a)

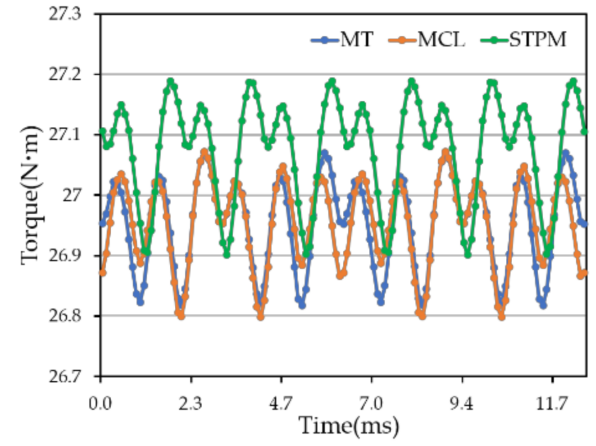

(b)

Figure 10. Electromagnetic torque: (a) NFT control; (b) MT control, MCL control and STPM control.

The torque harmonic under the four control modes is shown in Figure 11, it can be seen that the 2nd harmonic accounts for the largest as shown in Figure 11a, which is $6.75 \mathrm{~N} \cdot \mathrm{m}$, 
and followed by the 12th harmonic. According to the principle of constant MMF, the motor will output stable torque by MT control and MCL control after one-phase open circuit, but a large number of harmonics are generated. In Figure $11 \mathrm{~b}$, the torque harmonic distribution of MT control, MCL control and STPM control is $4 k f \mathrm{~Hz}, 2 k f \mathrm{~Hz}$, and $6 k f \mathrm{~Hz}$, and $k$ is natural number.

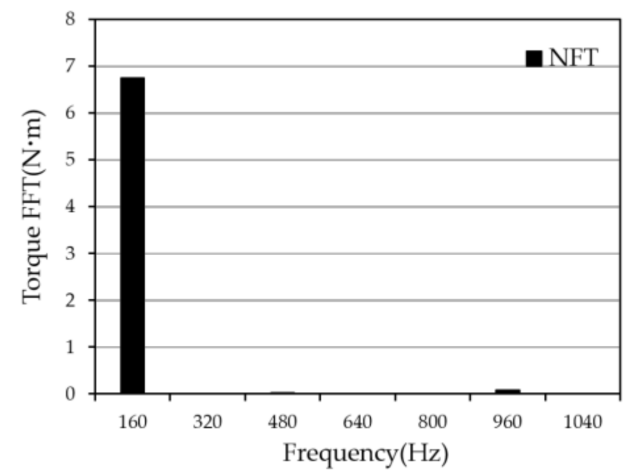

(a)

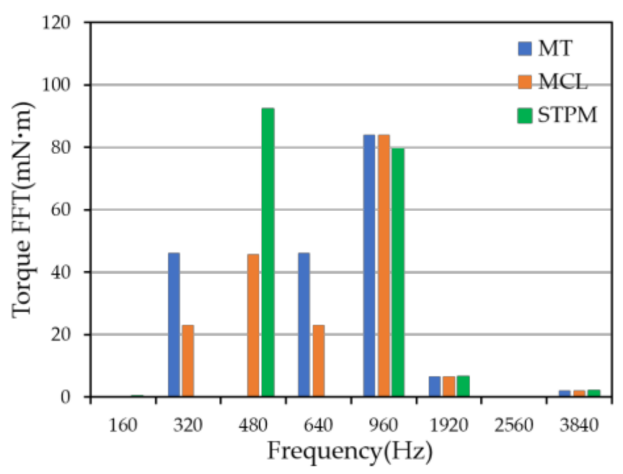

(b)

Figure 11. Torque harmonics: (a) NFT control; (b) MT, MCL and STPM control.

\subsection{Harmonic Analysis of Radial Electromagnetic Force}

Although the radial component and tangential component of electromagnetic force will cause radial vibration, generally, the radial component is much larger than the tangential component, so the contribution of tangential component and radial and tangential coupling of electromagnetic force can be ignored. Considering the tangential component of flux density, the radial electromagnetic force density in the air gap is calculated by the Maxwell tensor method [16], the results are shown in Figure 12. Asymmetric phase current leads to the temporal and spatial non-uniformity of radial electromagnetic force, which contains a large number of harmonics.

$$
F_{r}=\frac{B_{r}^{2}-B_{t}^{2}}{2 \mu_{0}}
$$

For the integer slot motor analyzed in this paper, because the lowest non-zero space order is $\operatorname{GCD}\left(2 p, Q_{s}\right)=16$, therefore, the 0th mode radial electromagnetic force is the main source of motor electromagnetic vibration and noise [16]. The electromagnetic force density distribution at spatial 0th mode is shown in Table 3, harmonic components with amplitude less than $0.5 \mathrm{~N} / \mathrm{m}^{2}$ in the results are not considered. It can be seen from Table 3 that when the motor adopts NFT control, the maximum radial electromagnetic force is 16th harmonic, the second maximum is 96th harmonic, and it contains a wealth of other orders. The electromagnetic force harmonics of MT control, MCL control and STPM control are distributed in $4 k p f r, 2 k p f r$ and $6 k p f r$, where $k$ is the natural number and $f r$ is the mechanical frequency of motor rotation, that can be calculated by $n_{r} / 60$.

Table 3. Electromagnetic force density distribution at spatial 0th mode.

\begin{tabular}{ccccc}
\hline Radial Force Density $\left(\mathbf{N} / \mathbf{m}^{\mathbf{2}}\right)$ & NFT & MT & MCL & STPM \\
\hline $16 f r$ & 4954 & - & - & - \\
$32 f r$ & 6.13 & 24.74 & 12.26 & - \\
$48 f r$ & 7.6 & - & 15.6 & 30.58 \\
$64 f r$ & 1.7 & 6.7 & 3.4 & - \\
$96 f r$ & 18.28 & 22.1 & 22.09 & 19.54 \\
$128 f r$ & 0.52 & 2.142 & 1.03 & - \\
$144 f r$ & - & - & 0.78 & 1.6 \\
\hline
\end{tabular}




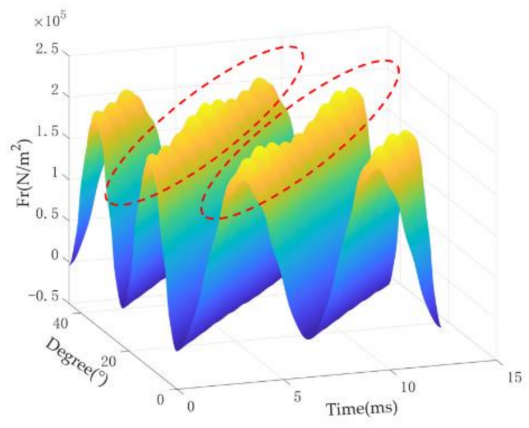

(a)

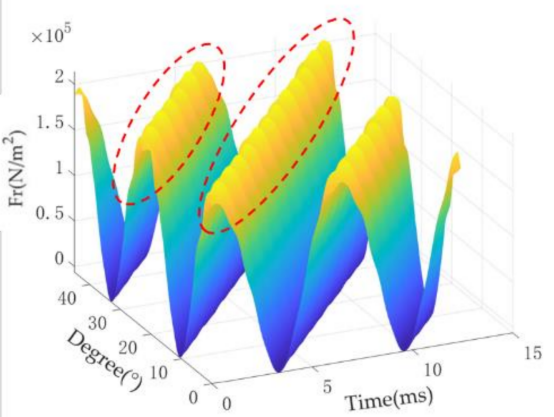

(c)

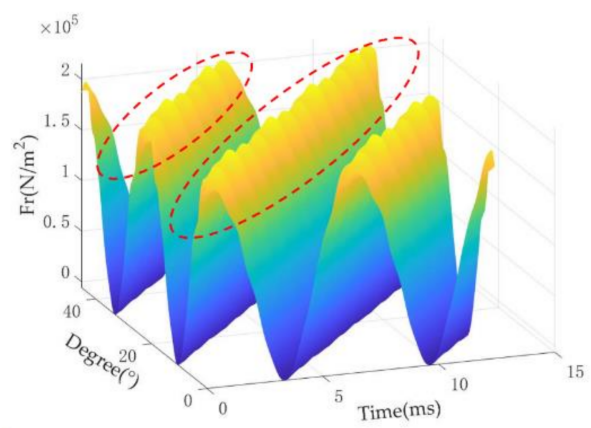

(b)

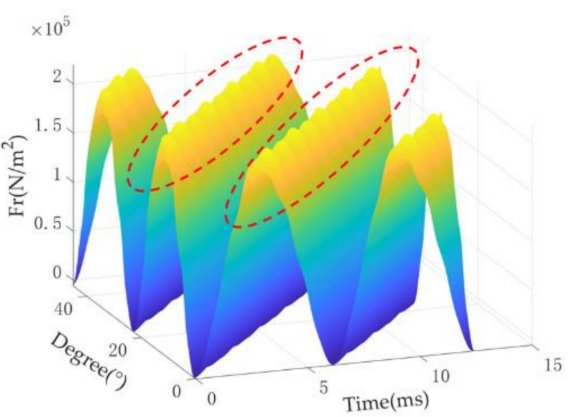

(d)

Figure 12. Radial electromagnetic force density after phase F open circuit fault: (a) NFT control; (b) MT control; (c) MCL control; (d) STPM control.

\section{Modal and Vibration}

\subsection{Modal Calculation of Stator Core}

The modal natural frequency is the natural property of the structure. When excited by the outside, the structure vibrates naturally according to the specific frequency. Therefore, an accurate structural model is very important for the prediction of electromagnetic vibration and noise. Due to the anisotropy of stator core materials, its parameters are shown in Table 4, and its modes are equivalent to stiffness and mass effects [17].

$$
f_{m}=\frac{1}{2 \pi}\left(\frac{K_{m}}{M_{m}}\right)^{1 / 2}
$$

Table 4. Equivalent material parameters of stator core.

\begin{tabular}{ccccc}
\hline $\begin{array}{c}\text { Material } \\
\text { Parameters }\end{array}$ & $\begin{array}{c}\text { Elasticity } \\
\text { Modulus (GPa) }\end{array}$ & $\begin{array}{c}\text { Shear Modulus } \\
\mathbf{( G P a )}\end{array}$ & Poisson Ratio & Density (kg/m $\left.\mathbf{m}^{\mathbf{3}}\right)$ \\
\hline Stator core & $\begin{array}{c}\mathrm{Ex}=\mathrm{Ey}=205.8 \\
\mathrm{Ez}=150\end{array}$ & $\begin{array}{c}\mathrm{Gxy}=80 \\
\mathrm{Gyz}=\mathrm{Gxz}=73\end{array}$ & 0.27 & 7650 \\
\hline
\end{tabular}

The stator modal shapes obtained by finite element calculation are shown in Figure 13. For the integer slot permanent magnet motor, the lowest non-zero order electromagnetic force is $2 p$, so 0 th mode is usually the main contributor to the low-frequency radiated vibration and noise spectrum. 


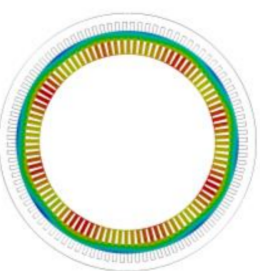

(a)

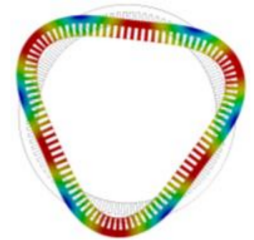

(d)

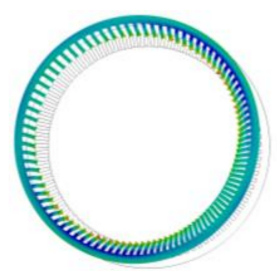

(b)

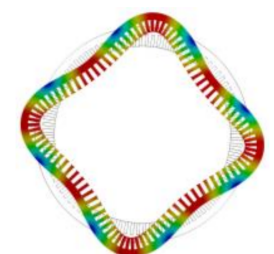

(e)

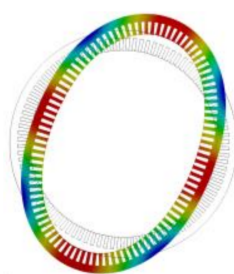

(c)

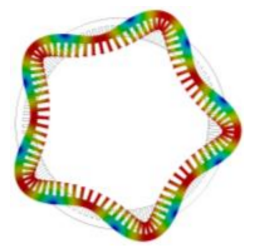

(f)

Figure 13. Modal shape: (a) Mode 0; (b) Mode 1; (c) Mode 2; (d) Mode 3; (e) Mode 4; (f) Mode 5.

The unconstrained free state of stator core is calculated in Table 5. The analytical calculation structure is similar to the finite element calculation structure, and the comparison error is within $5 \%$, so as to better ensure the rationality of the analytical calculation results of vibration and noise.

Table 5. Mode shape and mode frequency of stator.

\begin{tabular}{cccc}
\hline Mode Order & FEA (Hz) & Analytical (Hz) & Relative Error \\
\hline 0 & 3532.7 & 3566.2 & $0.95 \%$ \\
1 & 5082.6 & 4933 & $-2.94 \%$ \\
2 & 194 & 186.6 & $-3.8 \%$ \\
3 & 539.8 & 521.7 & $-3.36 \%$ \\
4 & 1013.5 & 984 & $-2.91 \%$ \\
5 & 1599.4 & 1559 & $-2.52 \%$ \\
6 & 2277.8 & 2233.2 & $-1.96 \%$ \\
7 & 3026.2 & 2992.05 & $-1.13 \%$ \\
\hline
\end{tabular}

\subsection{Electromagnetic Vibration}

The modal superposition method is used to simulate the harmonic response of electromagnetic and structural multi physical fields of damped stator core, when the stator core is subjected to electromagnetic excitation force, its vibration process can be expressed as Equation (22) [18]:

$$
\boldsymbol{M} \frac{d^{2} A_{d i s m}}{d t^{2}}+C \frac{d A_{d i s m}}{d t}+K A_{d i s m}=F_{m}
$$

where $M, C$, and $K$ represent the mass, the damping and the stiffness matrices, $F_{m}$ is the spatiotemporal harmonic vector of electromagnetic force. The vibration displacement $A_{\text {dism }}$ and acceleration $A_{a c c m}$ can be expressed as Equations (23) and (24) [18].

$$
\begin{aligned}
A_{\text {dism }}= & \frac{F_{m} / m_{s}}{\sqrt{\left(\omega_{m}^{2}-\omega_{r}^{2}\right)^{2}+4 \xi_{m}^{2} \omega_{r}^{2} \omega_{m}^{2}}} \\
& A_{\text {accm }}=\omega_{r}^{2} A_{\text {dism }} \\
& F_{m}=2 \pi R_{\text {air }} L_{s t} F_{r}
\end{aligned}
$$

where $m_{s}$ is the mass of stator core, $\omega_{r}$ is the electrical angular speed, and $\omega_{m}$ is m order modal angular frequency, $P_{r}$ is equivalent to the radial electromagnetic force density applied 
on the stator, $\xi_{m}$ is the m-mode circumferential modal damping coefficient [17], which can be calculated by empirical Formula (26), $f_{m}$ is the m order modal frequency.

$$
\xi_{m}=\frac{1}{2 \pi}\left(2.76 \times 10^{-5} f_{m}+0.062\right)
$$

When the motor runs at the speed of $600 \mathrm{r} / \mathrm{min}$, Figure 14 shows the comparison of motor vibration acceleration under different fault-tolerance strategies and normal operation. If fault-tolerant measures are not adopted as shown in Figure 14a, it can be seen that the motor will produce a large vibration at $16 f \mathrm{fr}$. The second frequency position that produces a large vibration is $96 f r$, it is caused by stator slotting and related to the number of motor slots. The third frequency position is $3520 \mathrm{~Hz}$, since it is close to the natural frequency of mode $0(3532.7 \mathrm{~Hz})$, although the electromagnetic force is very small, it can still produce a large vibration.

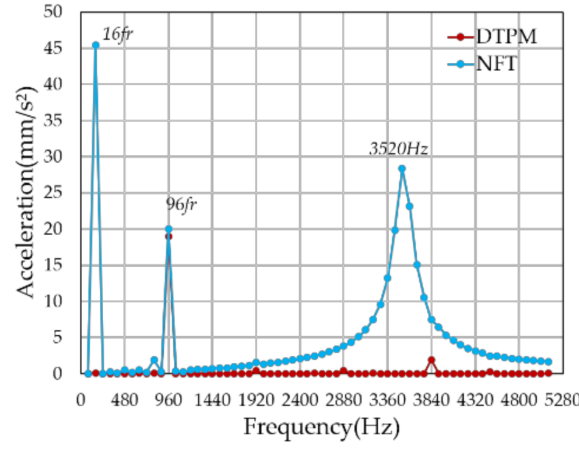

(a)

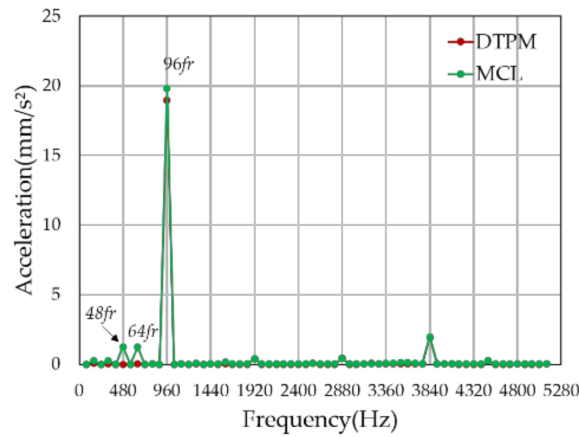

(c)

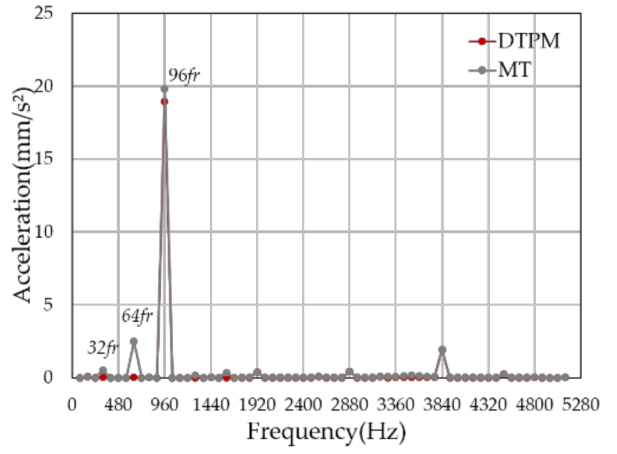

(b)

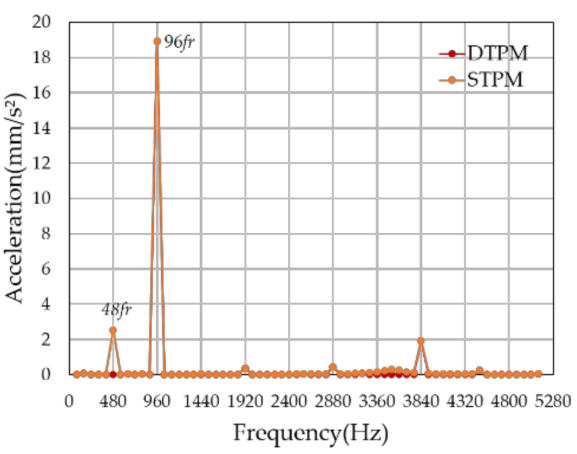

(d)

Figure 14. FE calculation results of vibration acceleration on stator core surface: (a) Comparison between NFT and DTPM; (b) Comparison between MT and DTPM; (c) Comparison between MCL and DTPM; (d) Comparison between STPM and DTPM.

When sinusoidal fault-tolerant current is applied, the vibration acceleration of stator surface under three working conditions is compared in Figure 14b-d. It can be seen that the maximum difference is in the frequency band within $1000 \mathrm{~Hz}$. Under the condition that the MMF remains unchanged and the output torque performance of the motor is the same, the frequency position of the maximum vibration of the motor is $96 \mathrm{fr}$, this is related to stator slotting, and its amplitude can be weakened by means of a slot skewed in the motor design.

In addition to the maximum vibration at $96 f r$, for MT control, vibration will be generated at 32fr and 64fr frequencies, MCL control will generate vibration at 32fr, 48fr and 64fr, while STPM control only generates vibration at $48 f r$, but the amplitude is larger than that of the first two fault-tolerant methods, the electromagnetic force harmonic distribution of the third-order analysis is verified. Although these frequencies are lower than the vibration generated at $96 \mathrm{fr}$ due to the motor slotting, the winding fault-tolerant current waveform 
is the result of sinusoidal. In practice, due to external factors, such as driver harmonics and mechanical reasons, it will be easier to interact with these order harmonics to produce greater vibration and noise.

In the intermediate frequency region, different fault-tolerant methods produce different components of electromagnetic force harmonics, which will cause the vibration of the corresponding harmonic frequency. Figure 15 shows the comparison of analytical and finite element calculation results under various working conditions, the calculation results of the two are similar, and the finite element calculation result is slightly larger than the analytical calculation result.

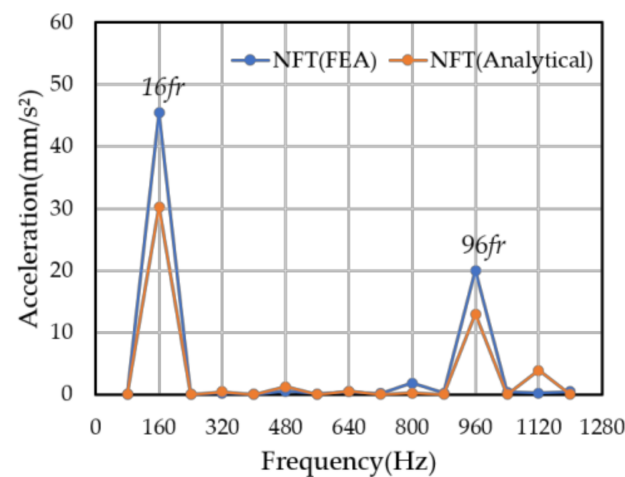

(a)

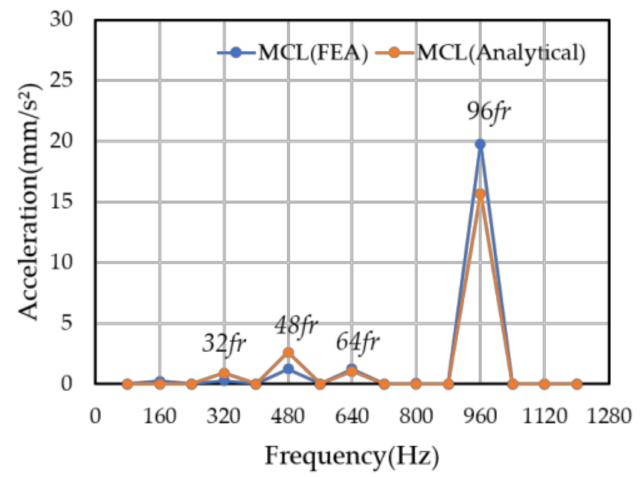

(c)

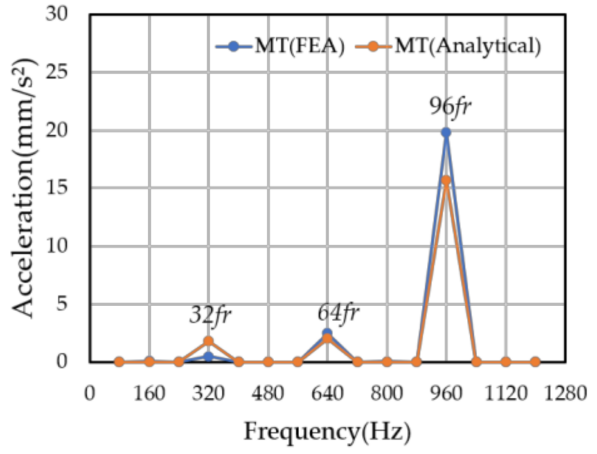

(b)

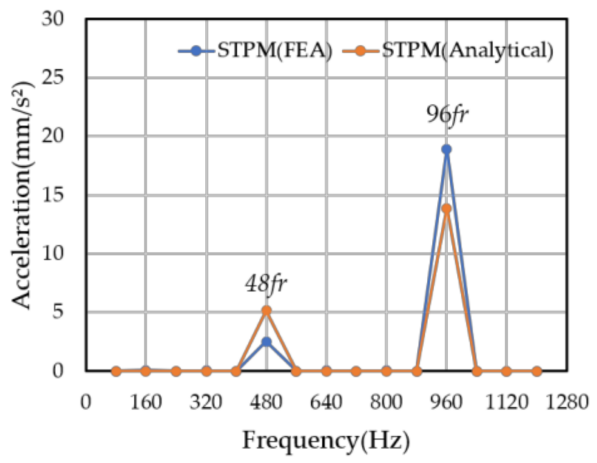

(d)

Figure 15. Comparison of vibration results between analytical method and FE method: (a) NFT control; (b) MT control; (c) MCL control; (d) STPM control.

\section{Conclusions}

In this paper, the magnetic field model of one-phase open circuit fault of low harmonic dual three-phase PMSM is established, based on the SM. It is assumed that the F-phase winding has an open circuit fault, the NFT control, MT control, MCL control and STPM control are considered, respectively. The torque harmonics and electromagnetic force harmonics under different working conditions are analyzed and the electromagnetic vibration is predicted. Analytical calculation results and finite element calculation results are compared to verify the accuracy of the established analytical model. By analyzing the motor harmonics and vibration distribution of different fault-tolerance methods, the following conclusions can be drawn:

- When there is an open-circuit failure of one-phase winding of the motor winding, if there is no fault-tolerance measure, the asymmetric armature current will cause the motor magnetic field to be asymmetric. A negative sequence magnetic field of order -1 will be generated, which will produce large torque ripple and vibration.

- Under the condition of the conservation of magnetomotive force, redistribute the current amplitude and phase so that the output torque of the motor can still be 
the same as before the fault. The maximum vibration produced by the motor is still the slot frequency vibration. The motor under MT control and MCL control produces a lot of low-frequency harmonic components. Although the amplitude of the vibration generated by these harmonics is not obvious compared with the slot frequency vibration, this is based on the assumption of windings. The current is sinusoidal, so these harmonics should not be ignored. Compared with MT and MCL control, STPM control will produce larger vibration at 48fr, but its harmonic component is single.

According to the integer slot Motor vibration and noise theory, if the motor vibration and noise performance is required, the motor should have fewer types of harmonics, and STPM control is more suitable. If the motor copper loss is required to be as low as possible, then MCL control has an advantage. The reliability of the established analysis method is verified by the structural parameters of 16 pole 96 slot motor. This analytical method is not limited to the analysis of motors with this structure. It is universal and can analyze double three-phase motors with other topologies.

Author Contributions: Conceptualization, S.Z. and J.C.; methodology, S.Z.; software, S.Z.; validation, S.Z., J.C., Y.G. and C.Z.; formal analysis, S.Z.; data curation, S.Z.; writing-original draft preparation, S.Z.; writing-review and editing, S.Z. and J.C.; funding acquisition, J.C. All authors have read and agreed to the published version of the manuscript.

Funding: This research was supported by the National Natural Science Foundation of China 51807194 in part by Ningbo major scientific and technological breakthrough under Grant 2021Z125, in part by Ningbo Science and technology innovation 2025 major special project $2020 Z 067$.

Institutional Review Board Statement: Not applicable.

Informed Consent Statement: Not applicable.

Data Availability Statement: The original data supporting the conclusion of this paper can be directly provided by authors.

Conflicts of Interest: The authors declare no conflict of interest.

\section{References}

1. Levi, E. Multiphase electric machines for variable-speed applications. IEEE Trans. Ind. Electron. 2008, 55, 1893-1909. [CrossRef]

2. Levi, E.; Barrero, F.; Martínez, M.J.D. Multiphase machines and drives-revisited. IEEE Trans. Ind. Electron. 2015, 63, 429-432. [CrossRef]

3. Zabaleta, M.; Levi, E.; Jones, M. A novel synthetic loading method for multiple three-phase winding electric machines. IEEE Trans. Energy Convers. 2019, 34, 70-78. [CrossRef]

4. Islam, R.; Husain, I. Analytical model for predicting noise and vibration in permanent-magnet synchronous motors. IEEE Trans. Ind. Appl. 2010, 46, 2346-2354. [CrossRef]

5. Zhu, Z.; Xia, Z.; Wu, L.; Jewell, G. Analytical modeling and finite-element computation of radial vibration force in fractional-slot permanent-magnet brushless machines. IEEE Trans. Ind. Appl. 2010, 46, 1908-1918. [CrossRef]

6. Wu, L.; Zhu, Z.; Staton, D.; Popescu, M.; Hawkins, D. An improved subdomain model for predicting magnetic field of surfacemounted permanent magnet machines accounting for tooth-tips. IEEE Trans. Magn. 2011, 47, 1693-1704. [CrossRef]

7. Le Besnerais, J. Vibroacoustic analysis of radial and tangential air-gap magnetic forces in permanent magnet synchronous machines. IEEE Trans. Magn. 2015, 51, 8105609. [CrossRef]

8. Guo, H.; Guo, S.; Xu, J.; Tian, X. Power switch open-circuit fault diagnosis of six-phase fault tolerant permanent magnet synchronous motor system under normal and fault-tolerant operation conditions using the average current park's vector approach. IEEE Trans. Power Electron. 2021, 36, 2641-2660. [CrossRef]

9. Li, W.; Feng, G.; Li, Z.; Tjong, J.; Kar, N. MultiReference frame based open phase fault modeling and control for asymmetrical six-phase interior permanent magnet motors. IEEE Trans. Power Electron. 2021, 36, 11712-11725. [CrossRef]

10. Fu, J.; Lipo, T. Disturbance-free operation of a multiphase current-regulated motor drive with an opened phase. IEEE Trans. Ind. Appl. 1994, 30, 1267-1274.

11. Hu, Y.; Feng, Y.; Li, X. Fault-tolerant hybrid current control of dual three-phase pmsm with one phase open. IEEE J. Emerg. Sel. Top. Power Electron. 2020, 9, 1591-1604. [CrossRef]

12. Yang, J.; Li, T.; Yang, G. Modeling and control of dual three-phase pmsm with one open phase. Trans. China Electrotech. Soc. 2011, 26, 167-173. 
13. Garcia-Entrambasaguas, P.; González-Prieto, I.; Duran, M. Single-Index open-phase fault detection method for six-phase electric drives. IEEE Trans. Ind. Electron. 2020, 67, 10233-10242. [CrossRef]

14. Wu, Z.; Gu, W.; Zhu, Y.; Lu, K. A novel open-phase fault detection method for dual Y shift 30 degrees permanent magnet synchronous motor. In Proceedings of the 2019 IEEE Vehicle Power and Propulsion Conference (VPPC), Hanoi, Vietnam, 14-17 October 2019; pp. 1-6.

15. Wang, Y.; Wen, X.; Zhao, F. The Fault-tolerant Control for Six-phase Permanent Magnet Synchronous Machines with One Phase Failure. Diangong Jishu Xuebao/Trans. China Electrotech. Soc. 2015, 30, 49-58.

16. Valavi, M.; Le Besnerais, J.; Nysveen, A. An investigation of zeroth-order radial magnetic forces in low-speed surface-mounted permanent magnet machines. IEEE Trans. Magn. 2016, 52, 8107206. [CrossRef]

17. Yang, S. Low-Noise Electrical Motors; Clarendon Press: Oxford, UK, 1981.

18. Gieras, J.; Wang, C.; Lai, J. Noise of Polyphase Electric Motors; CRC/Taylor \& Francis: Boca Raton, FL, USA, 2005. 